\title{
Responsabilidad patrimonial de la Administración por incumplimiento de los convenios urbanísticos en la reciente jurisprudencia del Tribunal Supremo
}

\author{
María José Alonso Mas \\ Profesora ayudante de Derecho Administrativo. \\ Universidad de Valencia
}

\begin{abstract}
Sumario: 1. INTRODUCCIÓN. 2. LA NATURALEZA JURÍDICA DE LOS CONVENIOS URBANISTICOS. 3. LA EFICACIA DE LOS CONVENIOS URBANISTICOS. 4. RÉGIMEN JURÍDICO APLICABLE A LA RESPONSABILIDAD DE LA ADMINISTRACIÓN POR INCUMPLIMIENTO DE LOS CONVENIOS URBANISTICOS. 5. EL CONTENIDO DE LA INDEMNIZACIÓN EN CASO DE INCUMPLIMIENTO DE CONVENIOS URBANÍSTICOS QUE AFECTEN A LA POTESTAD DE PLANEAMIENTO. 6. CONCURRENCIA DE RESPONSABILIDADES DE DISTINTAS ADMINISTRACIONES PÚBLICAS.
\end{abstract}

\section{INTRODUCCIÓN}

En algunas recientes sentencias se han suscitado problemas de responsabilidad patrimonial derivada del incumplimiento de convenios urbanísticos ${ }^{1}$. La

1 Para L. MARotTA, Pianificazione urbanistica e discrezionalità amministrativa, CEDAM, Padua, 1988, pág. 18, el ejercicio de la potestad de planificación supone la ponderación de intereses privados y públicos en conflicto, y sobre esa base normalmente estos últimos deben prevalecer, pero el sacrificio del interés privado debe estar suficientemente justificado sobre la base de esa ponderación. El autor, op. cit., pág. 105, añade que, para la jurisprudencia italiana, los intereses privados que se hallen amparados en un convenio urbanístico gozan de una particular resistencia, de modo que la Administración deberá probar la absoluta necesidad de su sacrificio y la imposibilidad de satisfacer de otro modo los intereses públicos de que se trate.

La STS de 5 de diciembre de 1994 afirma que un tercero puede ejercitar ante el orden judicial competente las acciones de responsabilidad por los daños causados a consecuencia de una licencia ilegal otorgada al amparo de un convenio urbanístico.

La STS de 25 de marzo de 1992 (A. 3387) se refería a la suspensión autonómica de un Plan general, al no ser el mismo acorde con las directrices de planeamiento territorial y urbanístico del área metropolitana, dados los gravísimos problemas de congestión urbanistica y deterioro medioambiental que se estaban produciendo. Esta suspensión impidió la ejecución de varios planes parciales; y con posterioridad a la misma se redactaron unas Normas subsidiarias. Entre la suspensión del plan y la aprobación de las referidas Normas, se celebró un convenio entre las Administraciones municipal y autonómica y los afectados por uno de los planes parciales, por el que se acordaba desclasificar el suelo de dicho plan parcial, 
cuestión presenta cierto interés, ya que, pese a la casuística regulación de la responsabilidad patrimonial de la Administración en la Ley del Suelo, ninguno de sus preceptos se dedica a dichos convenios.

Debe tenerse en cuenta que, si bien la responsabilidad patrimonial de la Administración urbanística posee reglas propias, la misma debe regirse por los principios inspiradores de los arts. 139 y ss. de la Ley $30 / 92^{2}$. De hecho, la STS de 31 de enero de 1995 (A. 457), referente a la pretensión indemnizatoria a consecuencia de la reducción del aprovechamiento urbanístico producida por el nuevo Plan general, tras concluir que el caso no era subsumible en el art. 87.2 del Texto Refundido de la Ley del Suelo de 1976, se preguntó si cabía aplicar los preceptos generales reguladores de la responsabilidad patrimonial de la Administración, si bien finalmente consideró que tampoco se daban los presupuestos para la aplicación de los mismos ${ }^{3}$.

Por otra parte, las sentencias que vamos a comentar dan pie a plantear otra importante problemática, como es la de la concurrencia de responsabilidades de distintas Administraciones Públicas a consecuencia del incumplimiento de convenios. En efecto, en algunas de ellas el incumplimiento se debe, bien a la aprobación definitiva de un nuev. plan por otra Administración, bien a la necesidad de incorporar el contenido del convenio, para su eficacia, a un plan posterior cuya aprobación definitiva es de la competencia de otra Administración, que deniega dicha aprobación definitiva.

\section{LA NATURALEZA JURIDICA DE LOS CONVENIOS URBANISTICOS}

El art. 303 del Texto Refundido de la Ley del Suelo califica todas las cuestiones que se susciten en relación con los convenios urbanísticos como jurídi-

pero transfiriendo su aprovechamiento urbanístico a otros terrenos propiedad de dichos afectados. Las previsiones del convenio se incorporaron a las ulteriores Normas subsidiarias. Los propietarios de los terrenos afectados por otro plan parcial alegaron desigualdad de tratamiento, pero su recurso fue desestimado porque este segundo plan parcial se hallaba en un grado de ejecución mucho menos avanzado en el momento de la suspensión del Plan general; de modo que, de acuerdo con el TS, el referido convenio era la única alternativa para evitar las indemnizaciones por cambio de planeamiento. En este caso, pues, no es que el incumplimiento del convenio originara un derecho a indemnización, sino que dicho convenio fue la vía para evitarla. Vid. asimismo STS de 6 de febrero de 1995 (A. 1071), referente a un convenio cuya finalidad fue evitar la expropiación forzosa de unos terrenos.

2 En favor de la aplicabilidad de los principios de la Ley 30/92 a los procedimientos tributarios, puede verse M. PONT MESTRES, Incidencia en los procedimientos tributarios de la Ley 30/92, de régimen juridico de las Administraciones Públicas y del procedimiento administrativo común, Marcial Pons, Madrid, 1995, págs. 27 y ss.

3 La STS de 19 de abril de 1995 (A. 3159) parece afirmar que todo acto urbanístico que cause un perjuicio puede dar lugar a una indemnización, aunque el supuesto no esté tipificado en la Ley del suelo. En este sentido puede verse asimismo M." J. MONTORO CHINER, La responsabilidad de la Administración por actos urbanisticos, Montecorvo, Madrid, 1983, pág. 49. 
RESPONSABILIDAD PATRIMONIAL DE LA ADMINISTRACIÓN ...

co-administrativas, lo que da pie a pensar que estos convenios tienen la naturaleza de contratos administrativos ${ }^{4}$. En efecto, la Ley 13/95, de contratos de las Administraciones Públicas, establece en su art. 5 el carácter administrativo de aquellos contratos vinculados al giro o tráfico de la Administración contratante por satisfacer de modo directo o inmediato una finalidad pública de su competencia; una de estas finalidades públicas puede ser la ejecución del planeamiento ${ }^{5}$.

En todo caso, se trata de contratos muy peculiares, ya que en la medida en que los mismos pretendan una modificación del planeamiento, no vinculan a la Administración, ni siquiera a la que los han suscrito, hasta tanto se apruebe dicha modificación, sin perjuicio de la posible exigencia de responsabilidades; además, se rigen por su normativa específica, cuando la haya, de modo que se pueden entender como contratos administrativos sui generis ${ }^{6}$. De cualquier modo, la STS de 7 de noviembre de 1990 (A. 8805), referente a un convenio por el que el Ayuntamiento se comprometía a gestionar ante la Corporación metropolitana de Barcelona que la revisión del Plan comarcal, ya aprobada inicialmente, contuviera ciertas previsiones, entendió que el acuerdo constituía un contrato, si bien en el mismo se sometía el cumplimiento de las obligaciones derivadas del mismo para el particular - y consistentes en la cesión gratuita de unos terrenos - a la condición de que el referido Plan se aprobara definitivamente incorporando las previsiones convenidas. En suma, el TS entendió que se trataba de un contrato válido y eficaz ${ }^{7}$.

4 Resalta J. AROzAMENa SIERRA, «Algunas consideraciones sobre la institución contractual y el urbanismo: los llamados convenios urbanisticos», en $R D U, \mathrm{n} .^{\circ} 146,1996$, pág. 24, que el art. 3 de la Ley 13/95 no los excluye expresamente de su ámbito de aplicación.

Según J. L. LOPEz PELLICER, «Naturaleza, supuestos y limites de los convenios urbanisticos», en $R D U$, n. ${ }^{\circ} 146,1996$, pág. 130, debido a la heterogeneidad de figuras incluidas en el ámbito de los convenios urbanísticos, algunos de ellos se podrán entender como contratos administrativos, pero otros serán convenios de colaboración.

5 En todo caso, afirma J. R. Parada VäzQuez, Derecho Administrativo, Parte general, 7.a ed., Marcial Pons, Madrid, 1995, págs. 276-77, que el art. 2 de la Ley 13/95 excluye de la aplicación de la legislación de contratos administrativos ciertos convenios que la Administración celebra con los particulares a los que, pese a tener origen bilateral, no son aplicables los sistemas de selección de contratistas, las garantías de la contratación y la restante normativa de la contratación pública por el propio contenido de tales convenios. El autor no cita entre éstos los convenios urbanisticos, sino que hace referencia, entre otros, a los expropiatorios o a los de precios; y añade que no se trata de contratos administrativos porque la Administración se halla en los mismos en una posición de superioridad sobre los particulares con los que conviene. Esto no ocurre en todos los convenios urbanísticos.

6 En este sentido, P. Martín Hernández, «Los convenios urbanisticos», en RDU, n. ${ }^{\circ} 144,1995$, pág. 60.

7 La sentencia declaró el derecho del recurrente a la retrocesión del suelo cedido, ya que la condición establecida en el contrato para el cumplimiento de la obligación de cesión no se había cumplido, sino que la cesión se habia llevado a efecto por error en la certificación municipal relativa al cumplimiento de la misma. En realidad, lo que ocurre es que este tipo de condiciones están implícitas en todo convenio urbanistico en que se pretende una modificación del planeamiento vigente. 
No obstante, en ocasiones se afirma que el convenio urbanístico constituye un caso de terminación convencional del procedimiento ${ }^{8}$. Propiamente los convenios, al menos los que pretenden una modificación del planeamiento, no concluyen por sí mismos el procedimiento, ya que necesitan incorporarse a un plan para ser eficaces, pero podría no obstante entenderse que constituyen un caso de terminación convencional en su modalidad de propuesta no vinculante para la Administración. Sin embargo, LÓPEZ PELICER ${ }^{9}$ señala que este supuesto no constituye propiamente una terminación convencional ${ }^{10}$.

8 Puede en este sentido consultarse T.R. FERNÁNDEZ RoDriguEZ, Manual de Derecho Urbanistico, 10. ed., Abella, Madrid, 1993, pág. 192.

9 López Pellicer, op. cit., pág. 117. Según este autor, op. cit., pág. 113, cuando se estipulan ciertos compromisos entre el urbanizador y el Ayuntamiento que después deberán incorporarse para su eficacia a un futuro plan, no estamos ante ninguno de los casos del art. 88 de la Ley 30/92, ya que el compromiso debe someterse al procedimiento de aprobación del plan y además se refiere a un elemento de éste y no al mismo en su conjunto. Para este autor, op. cit., pág. 106, los únicos supuestos en que el convenio urbanístico puede ser sustitutivo del acto que pone fin al procedimiento son los convenios expropiatorios referentes al justiprecio, por aplicacion del art. 24 de la LEF, y los casos en que se conviene con las partes la cuantía de la indemnización en caso de revocación, denegación o demora injustificada en el otorgamiento de licencias, ya que son subsumibles en los convenios indemnizatorios regulados en el Real Decreto 429/93 de 26 de marzo. Entiende no obstante el autor que no nos encontramos aqui propiamente ante convenios urbanisticos, por cuanto se regulan por una normativa diferente. $Y$, en relación con los que se insertan en el procedimiento a modo de propuesta vinculante, afirma que quizás el único caso en el ámbito urbanístico sea el previsto en el art. 155.2 del TRLS, referente al pago de los costes de urbanización con terrenos edificables.

10 Para L. PARejo Alfonso, «La terminación convencional del procedimiento administrativo como forma altemativa de desarrollo de la actividad unilateral de la Administración', en Eficacia y Administración. Tres estudios, INAP-BOE, Madrid, 1995, pág. 170 —n el mismo sentido, J. R. PARADA VázQUEz, Régimen juridico de las Administraciones Públicas y del procedimiento administrativo común, Marcial Pons, Madrid, 1993, págs. 308 y ss.- la terminación convencional no es sino un sustitutivo del acto administrativo unilateral, ya que entiende que dicha terminación muchas veces no busca la colaboración de los particulares para lograr algo que la Administración no puede compeler a hacer sino que, por el contrario, sustituye en ocasiones a una decisión administrativa unilateral con el fin de lograr una mayor eficacia. Es por ejemplo el supuesto en que la Administración adquiere por convenio ciertos terrenos que en principio deberian haber sido objeto de cesión gratuita. Vid, por ejemplo, STS de 29 de marzo de 1995 (A. 4163).

En el caso resuelto por la STS de 16 de noviembre de 1993 (A. 8217) el Ayuntamiento, durante la tramitación del Plan general, convino con una sociedad la clasificación como urbanos de los terrenos de ésta a cambio de la cesión de ciertos terrenos y una cantidad de dinero. En este supuesto, el convenio no sustituye una actuación unilateral, ya que el Ayuntamiento sólo puede obtener gratuitamente terrenos en los casos señalados en la legislación urbanistica. Sin embargo, lo cierto es que a través de éxpropiación tales terrenos se podrian haber obtenido, aunque el procedimiento habria sido más largo y costoso y habria supuesto además un sacrificio para el Erario público. Pero en todo caso, el fin se podría haber conseguido a través del acto unilateral expropiatorio. Puede verse también la STS de 30 de marzo de 1993 (A. 1785), referente a un convenio para la sustitución de parte del justiprecio de una expropiación por un incremento del volumen edificable. En este caso, la expropiación era suficiente para conseguir una finalidad pública, pero excesivamente onerosa para el Erario público, y de ahi el convenio posterior.

Por el contrario, en la STS de 23 de febrero de 1993 (A. 851), se trataba de un convenio urbanistico por el que se sustituía el sistema de expropiación por el de compensación. En este caso, el convenio no sustituye a decisión unilateral alguna, ya que la Administración no puede imponer el sistema de compensación. 


\section{LA EFICACIA DE LOS CONVENIOS URBANÍSTICOS}

Con carácter previo al estudio del tema que nos ocupa, debe plantearse el tema de la eficacia vinculante de los convenios urbanísticos. Sin embargo, dicha eficacia no puede estudiarse de modo unitario, ya que existen distintos tipos de convenios, y cada uno de esos tipos posee una eficacia diferente.

La clasificación que más nos interesa es la que atiende a si el convenio pretende o no una modificación del planeamiento ${ }^{11}$. En efecto, existen convenios urbanísticos cuya pretensión únicamente es facilitar la gestión del suelo y la ejecución del planeamiento vigente, sin que se pretenda una modificación del mismo. Estos convenios en este momento no nos interesan, ya que las sentencias que vamos a comentar no se refieren a ellos, y además resultan menos problemáticos que aquellos que sí pretenden un cambio en el planeamiento ${ }^{12}$.

Otros convenios, por el contrario, pretenden una modificación del planeamiento vigente. Los mismos, naturalmente, tienen como objetivo final, al igual que los restantes convenios urbanísticos, favorecer una más eficaz gestión del suelo, pero es posible que, para lograr ese objetivo, el medio sea

La STS de 6 de marzo de 1993 (A. 1591) se refería a un convenio urbanístico por el que se adoptaba como sistema de actuación la reparcelación discontinua con transferencias de aprovechamientos. En este supuesto, el fin legal se habría conseguido por cualquiera de los sistemas de actuación previstos legalmente, pero se optó por éste en aras de una mayor eficacia. En todo caso, pensemos que el Ayuntamiento no puede imponer la compensación, y que la expropiación estaba prevista en el TRLS de 1976 como sistema subsidiario.

En todo caso, esta tesis de Parejo Alfonso no nos debe hacer olvidar la indisponibilidad del poder público. La STS de 15 de febrero de 1994 seffala que tales convenios no pueden "condicionar el ejercicio de las potestades urbanísticas, por ser el urbanismo una auténtica función pública indisponible e irrenunciable».

11 La Ley navarra 10/94, de 4 de julio, distingue en su art. 140 entre ambos tipos de convenios. La Disposición Adicional Cuarta de la Ley valenciana 4/92, del suelo no urbanizable, distingue entre los convenios que se suscriban con motivo de y en relación con la ejecución de un plan, que no pueden alterar el planeamiento, y los convenios que se suscriban con motivo de la formulación de un plan. Para estos últimos, la Disposición establece que tales convenios se entienden sin perjuicio de la plenitud de la potestad de planeamiento.

Por su parte, en la Ley madrilefia de 25 de marzo de 1995, art. 74, se distingue entre los convenios cuyo objeto sean las técnicas y condiciones de la gestión y ejecución del planeamiento de aquellos otros cuyo contenido sean las posibles modificaciones futuras del planeamiento, bien directamente, bien en la medida en que las mismas sean precisas para el cumplimiento de tales convenios.

12 De acuerdo con Martín Hernández, op. cit., pág. 82, los convenios relativos a la ejecución del planeamiento sólo adquieren virtualidad desde el momento en que se incorporan a instrumentos formales para dicha ejecución, como un proyecto de compensación o de reparcelación, pero añade que en las legislaciones autonómicas vigentes estos últimos instrumentos pueden sustituirse por el contenido del propio convenio. 
REALA 271-272 (JULIO-DICIEMBRE, 1996)

modificar el planeamiento. Las sentencias que vamos a estudiar se refieren a este tipo de convenios.

Los mismos resultan más problemáticos que los anteriores en cuanto a su eficacia. En efecto, el Tribunal Supremo afirma reiteradamente que los convenios no pueden suponer una disposición de la potestad de planeamiento, que es inalienable ${ }^{13}$. La indisponibilidad de la potestad de planeamiento es una consecuencia de su misma naturaleza de potestad, que se confiere en aras de los también indisponibles intereses públicos.

Es particularmente claro el art. 74 de la Ley madrileña de 25 de marzo de 1995 , en el que se establece que los convenios cuyo objeto sea procurar una modificación del planeamiento sólo vinculan a iniciar y tramitar los procedimientos de modificación, pero sin que los mismos vinculen a la potestad de planeamiento, ni siquiera de la Administración que los haya suscrito inicialmente ${ }^{14}$. El art. 75 instrumenta esta disposición señalando que el texto definitivo de los convenios, una vez incorporado su texto inicial a la documentación del plan y sometido a información pública, debe ratificarse por la Administración que inicialmente los haya suscrito. Lo mismo se establece en el art. 141.3 de la Ley navarra $6 / 94^{15}$. El art. 141.4 de esta última dispone que los convenios se perfeccionan y obligan desde su firma, tras la aprobación de su texto definitivo en la forma señalada en el apartado tercero del precepto.

Esta inalienabilidad de la potestad de planeamiento por vía convencional se evidencia, por ejemplo, en la STS de 30 de abril de 1979 (A. 1592). Se trataba de un convenio por el que unos particulares, que habían efectuado unas construcciones ilegales, se comprometían a pagar al Ayuntamiento unas cantidades y a urbanizar a su costa una zona a cambio de la no demolición de aquéllas. Es decir, el Ayuntamiento se había comprometido a modificar el planeamiento con el fin de legalizar esas construcciones. El TS entendió que el contrato era de objeto ilícito, ya que la potestad de planeamiento se halla fuera del tráfico jurídico.

13 Vid. la STS de 23 de junio de 1994 (A. 5339), donde se señala que la existencia de un acuerdo previo no puede alterar las normas de procedimiento para la elaboración de los planes de urbanismo, introduciendo por ejemplo la exigencia de notificaciones personales.

La STS de 15 de diciembre de 1993 (A. 9561), referente a la revision de un Plan general, afirma que los convenios en si carecen de fuerza obligatoria, pero en cuanto que se incorporan a un Plan adquieren la fuerza y la eficacia de éste. Vid. asimismo la de 29 de noviembre de 1993 (A. 9062).

14 Lo mismo se establece en el art. 140.5 de la Ley foral 6/94.

Para AROzAmena Sierra, op. cit., pág. 23, la jurisprudencia no permite la alienación de la potestad de planeamiento, pero si que convencionalmente se asuma el compromiso de modificarlo.

15 En todo caso, del art. 74 se desprende contrario sensu, y como no podia ser menos, que la suscripción de un convenio no vincula a la otra Administración que tenga asimismo competencias en relación con el plan de que se trate. Vid. asimismo el art. 140.5 de la Ley foral $6 / 94$. 
En muchas otras sentencias se afirma la indisponibilidad de la potestad de planeamiento a través de los convenios urbanísticos. Sin embargo, resulta más raro que en las mismas se declare la nulidad de un convenio por implicar el mismo una disposición de esa potestad. Lo que ocurre es que los presupuestos de hecho de una y otras son diferentes. En general, casi todas las sentencias en las que se plantea la eficacia vinculante de los convenios urbanísticos, son los particulares los que pretenden hacerlos valer, tratando de impedir modificaciones ulteriores del planeamiento que inciden sobre tales convenios. En tales casos, basta con afirmar que los mismos no vinculan al planeamiento posterior. En cambio, en el caso de la sentencia de 30 de abril de 1979, la Administración era la que había intentado hacer valer el convenio para exigir el pago de las cantidades adeudadas de conformidad con el mismo.

En realidad, lo que ocurría en este caso, a mi modo de ver, es que estas cantidades sólo habrían sido exigibles si hubiera prosperado la modificación del plan, ya que sólo entonces la Administración habría cumplido dicho convenio. Es decir, es verdad que el mismo no vincula a la Administración a modificar el planeamiento, pero ello no obsta a que si la modificación hubiera prosperado, el convenio hubiera sido cumplido.

La cuestión es si cabe deducir responsabilidades en caso de que la Administración cambie de criterio e incumpla estos convenios urbanísticos, habida cuenta que la doctrina entiende posible que exista responsabilidad administrativa por actos lícitos. De hecho, muchas sentencias del TS entienden posible la concurrencia de esta responsabilidad cuando se incumple el convenio ${ }^{16}$. En este caso, eventualmente podríamos estar ante un caso de responsabilidad por actos normativos lícitos ${ }^{17}$.

16 La STS de 20 de diciembre de 1991 (A. 314, 1992), en relación con la aprobación definitiva de unas Normas subsidiarias, afirma que si bien el interés público urbanistico implica que la potestas variandi no puede encontrar su límite en los convenios preexistentes, no obstante en caso de incumplimiento del convenio por alteración del plan cabrían eventualmente indemnizaciones. Lò mismo afirma la de 13 de julio de 1990 (A. 6034) y la de 21 de septiembre de 1991 (A. 6818).

La STS de 13 de febrero de 1992 (A. 2828) afirma que no se puede disponer de la potestad de planeamiento por vía contractual, sin perjuicio de la posibilidad de indemnizaciones. Vid. asimismo la de 15 de abril de 1992 (A. 4051).

17 Véase A. Blasco EsTEVE, La responsabilidad de la Administración por actos administrativos, Civitas, Madrid, 1981, págs. 76 y ss. y 170 y ss., quien cita entre otras la STS de 27 de enero de 1971 (A. 284). El autor se basa en el carácter objetivo de la responsabilidad y en el hecho de que la misma procede también por el funcionamiento normal del servicio público. En todo caso, resalta que en nuestra jurisprudencia se ha interpretado restrictivamente esta posibilidad, ya que existe una tendencia a identificar los actos licitos con la existencia de un deber juridico de soportar el daño. Añade, op. cit., pág. 183, que, a su juicio, debe disociarse el deber de soportar que la Administración ejercite la potestad del deber de soportar sin compensación el dafio causado por dicho ejercicio. Entiende así que el criterio determinante es el del sacrificio especial, si bien artade que en ocasiones la indemnizabilidad se excluye expresamente por el Ordenamiento. 
Sí es cierto, en todo caso, que en ocasiones las leyes autonómicas limitan o excluyen la responsabilidad administrativa por incumplimiento de los convenios urbanísticos que afectan a la potestad de planeamiento. Tal es el caso, por ejemplo, de la Disposición Adicional Cuarta de la Ley valenciana 4/92, de 5 de junio, del suelo no urbanizable. En dicha Disposición se establece, respecto de los convenios que se suscriban con motivo de la formulación de planes urbanísticos, que su eficacia se entiende subordinada a la condición suspensiva de que el plan definitivamente aprobado haga posible su cumplimiento; y añade que el incumplimiento de esta condición no generará responsabilidad contractual, aunque el cambio de criterio sea imputable a la Administración y no esté justificado ${ }^{18}$.

La cuestión radica en saber si las Comunidades Autónomas tienen competencia para establecer una disposición semejante, habida cuenta de la competencia estatal exclusiva para legislar sobre el sistema de responsabilidad de las Administraciones Públicas. El problema radica en que esta responsabilidad es contractual, y las Comunidades Autónomas ostentan competencias para el desarrollo de las bases estatales de la contratación administrativa; así, se plantea si esta cuestión es subsumible en la competencia estatal sobre el sistema de responsabilidad administrativa o más bien entraría dentro de la contratación administrativa, donde a su vez habría que distinguir entre bases y desarrollo.

En todo caso, la Disposición Final de la Ley 13/95, de contratos de las Administraciones Públicas, establece su carácter básico, sin exceptuar del mismo preceptos como el art. 100, el 114.3 y el 166, que regulan precisamente supuestos de responsabilidad administrativa por incumplimientos contractuales. Parece pues que el legislador estatal entiende que la responsabilidad administrativa contractual entra dentro de las bases de la contratación administrativa; desde esta perspectiva, el legislador autonómico carecería de competencia para regularla. Y ello, aunque exista un título superpuesto, como es la competencia de las Comunidades Autónomas sobre el urbanismo ${ }^{19}$. De este modo, posiblemente

En todo caso, LOPEZ PeuLCER, op. cit., pág. 127, con referencia a esta Ley, afirma que la responsabili-
dad administrativa derivada del incumplimiento de un convenio no debería entenderse contractual, sino
que la regulación aplicable debe ser la de los arts. $139 \mathrm{ss.} \mathrm{de} \mathrm{la} \mathrm{Ley} 30 / 92$ cuando el supuesto no sea
subsumible en los arts. 237 y ss. del TRLS. En todo caso, el autor, op. cit., pág. 127, afirma, con
referencia a la Ley valenciana $6 / 94$, de actuaciones urbanisticas -cuya Disposición Adicional Sexta
se remite a la Ley $4 / 92-$, que la previsión que en la misma se efectua de la indisponibilidad en la potestad
de planeamiento no se compagina bien con la de la responsabilidad de la Administración en caso de que la
suscripción del convenio se condicione a la aprobación del programa conforme al cual aquél se estipula y
después aquél no se apruebe -un caso distinto sería, a su juicio, cuando un plan posterior hiciera inviable
el contenido del convenio-.
19 La STC $213 / 88$ de 11 de noviembre declaró inconstitucionales ciertos preceptos de la Ley catalana 
RESPONSABILIDAD PATRIMONIAL DE LA ADMINISTRACIÓN ...

haya que concluir que el legislador valenciano incurrió en este punto en extralimitación competencial.

\section{RÉGIMEN JURÍDICO APLICABLE A LA RESPONSABILIDAD DE LA ADMINISTRACIÓN POR INCUMPLIMIENTO DE LOS CONVENIOS URBANISTICOS}

Hemos de preguntarnos si, en caso de incumplimiento de un convenio urbanístico, la regulación aplicable a la responsabilidad de la Administración es la prevista en la Ley del Suelo o si, por el contrario, se trata de una modalidad de responsabilidad contractual; a su vez, en este último caso, podríamos preguntarnos si la misma se rige por las normas jurídico-civiles - arts. 1101 y siguientes del Código Civil-o, por el contrario, por normas jurídico-administrativas, como las de la Ley 13/95 —arts. 98, y 114 y 103, entre otros, reguladores de la responsabilidad de la Administración y del contratista en relación con los terceros y de aquélla en relación con el contratista-. De cualquier modo, dada la parquedad de estas últimas las más de las veces habrá que acudir, con carácter supletorio, a la legislación civil —art. 7 de la Ley 13/95-.

La STS de 18 de julio de 1994 (A. 5543) resuelve esta cuestión señalando que no eran de aplicación al caso resuelto por la misma las normas recogidas en el art. 87 de la Ley del Suelo de 1976, al tratarse de una actuación de tipo contractual. Se trataba de un convenio urbanístico de cesión de terrenos para la edificación de un grupo escolar a cambio del reconocimiento de la edificabilidad en el resto de los terrenos para la construcción de viviendas, estando vigente la Ley del Suelo de 1956, según la cual los terrenos destinados a grupos escolares se obtenían por expropiación. Presentado un proyecto por el propietario en que se recogían ciertas modificaciones, se aprobó el proyecto y se aceptó la cesión.

Al resultar ocupados por el grupo escolar más terrenos de los pactados, se solicitó un aumento del volumen edificable, lo que fue denegado, por lo que se presentó un nuevo proyecto en sustitución del anterior, que el Ayuntamiento aprobó como "plan de ordenación de masas» en sustitución del anteriormente aprobado; pero se denegó la aprobación definitiva por el Ministerio, que con posterioridad lo aprobó como plan parcial con ciertas modificaciones, que suponían una disminución del volumen edificable. Vendidos los terrenos, los

de urbanismo por cuanto regulaban el régimen de suspensión de actos urbanisticos de modo distinto al establecido en la Ley 7/85. Es decir, otorgó prioridad al título competencial de las bases del régimen juridico de las Administraciones Públicas sobre el del urbanismo. 
herederos del propietario solicitaron el abono de la diferencia de volumen y, en su defecto, el justiprecio de los terrenos del grupo escolar.

EI TS afirmó que, al tratarse de un convenio previo al inicio del expediente expropiatorio, estamos ante un contrato asimilable a la compraventa o permuta, si bien de naturaleza administrativa ${ }^{20}$. Entiende que debía determinarse si existió o no un incumplimiento culpable y un daño conectado causalmente con dicho incumplimiento. Afirma así que estamos ante una relación administrativa contractual $^{21}$.

20 En relación con esto, la Ley de contratos del Estado de 1973, vigente en aquel momento, establecia en su art. 4.2 el carácter administrativo de los contratos de contenido patrimonial directamente vinculados a un servicio público. En la actualidad, el art. 5.3 de la Ley 13/95 afirma que son contratos privados los de permuta y compraventa de bienes inmuebles. No obstante, en este caso cabía afirmar el carácter administrativo del contrato, dada su vinculación a la función pública urbanistica. Además, la jurisprudencia siempre ha entendido de modo muy amplio la noción de contrato administrativo: pensemos por ejemplo en la STS de 8 de marzo de 1986 (A. 1773), sobre el arrendamiento de la plaza de toros de Las Ventas.

La LRJAE, vigente en el momento en que tuvieron lugar los hechos litigiosos - sobre la aplicabilidad como regla general de las normas vigentes en el momento en que se produce un presupuesto de hecho, L. M. Diez-Picazo Giménez, La derogación de las leyes, Civitas, Madrid, 1990, págs. 203 y ss._, establecia en su art. 41 que, cuando la Administración actuara en relaciones de Derecho privado, la responsabilidad se exigiria ante los Tribunales ordinarios; lo que hizo entender a algunos que, en estos casos, cabria considerar que dicha responsabilidad se regiria por las normas del Código Civil -sobre estas cuestiones, véase S. MuÑoz MACHADO, La responsabilidad civil concurrente de las Administraciones Públicas, Civitas, Madrid, 1992, págs. 95 y ss. - No obstante, en la sentencia que comentamos se afirma que el convenio litigioso era un contrato administrativo, y no un contrato privado. Además, el art. 303 del TRLS de 1992 establece que tendrán carácter administrativo las cuestiones derivadas de los convenios urbanisticos. Lo mismo disponía el art. 234 del TRLS de 1976. Vid. asimismo el art. 77 de la Ley madrileña de 25 de marzo de 1995.

21 Existen ciertas diferencias con la responsabilidad contractual civil por lo que a la Administración respecta; la prueba la tenemos en que el art. 114 habla de la responsabilidad por incumplimiento culpable del contratista y no emplea este adjetivo para referirse a los incumplimientos de la Administración contratante que ocasionan responsabilidad; si bien es cierto que la jurisprudencia civil suele relativizar el requisito de la culpabilidad. Ya en el art. 53 de la Ley de contratos del Estado de 1973, entonces vigente, se hablaba de incumplimientos culpables del contratista sin hacer referencia a la culpabilidad de la Administración a la hora de exigirle responsabilidades, al igual que en la vigente.

Es cierto que el art. 99 de la Ley $13 / 95$ establece que el riesgo y ventura del contrato corre a cargo del contratista, salvo lo dispuesto en la misma para el contrato de obras. Tarnbién lo es que, en los contratos administrativos, la Administración responde en los casos de factum principis, que es ajeno al contrato, en los de ejercicio del ius variandi — con matices para los casos de supresión de unidades de obra-, y en los supuestos de riesgo imprevisible. Los dos primeros casos no son de responsabilidad objetiva, sino por actos voluntarios. Por lo que respecta al riesgo imprevisible, se trata de factores objetivos ajenos al contrato; pero justamente se excluye la responsabilidad de la Administración en caso de hechos objetivos no imprevisibles. No obstante, nos podemos preguntar si la Administración responde por hechos derivados del funcionamiento del servicio público aun cuando no medie culpa propiamente dicha. Entiendo que sí, a la vista de la regulación en caso de demora en el pago al contratista. Esta demora puede no deberse a culpa de la Administración contratista; por ejemplo, en caso de que el Ayuntamiento se demora en el pago por a su vez haberse retrasado el Estado en abonarle las cantidades que todos los antos transfiere a los municipios. Pero, en todo caso, los incumplimientos debidos al funcionamiento de los servicios públicos constituyen casos de responsabilidad por el funcionamiento de los citados servicios, si bien 
RESPONSABILIDAD PATRIMONLAL DE LA ADMINISTRACIÓN ...

La sentencia concluyó que había habido un incumplimiento culpable del Ayuntamiento porque la no concesión del volumen se debe a que prometió algo que no dependía de él, al estar sujeto a la aprobación del Ministerio; y añadió que se produjo un daño pese a la venta de los terrenos, ya que el precio de la compraventa fue inferior al que podría haber sido de no haberse disminuido la edificabilidad.

Semejante a la STS de 18 de julio de 1994 es la STS de 15 de febrero de 1994 (A. 1448). Se trataba de un acuerdo de cesión gratuita de solar a cambio de acumular el volumen edificable al de otra parcela, al que se trasladó su aprovechamiento - es decir, de una TAU efectuada a través de convenio-. Pero el aprovechamiento materializable en la segunda se redujo a consecuencia de las nuevas Normas subsidiarias. Solicitada la retrocesión del suelo cedido, se estimó que el convenio generaba únicamente una expectativa, al no haberse cumplido las cargas legales, por lo que se apreció indiligencia del recurrente. De este modo, el TS declaró la inexistencia de responsabilidad patrimonial de la Administración.

Esta sentencia entendió, al igual que la que acabamos de comentar, que no resultaba aplicable el art. 87 de la entonces vigente Ley del Suelo de 1976, si bien lo fundamenta no tanto en la existencia de un acuerdo de voluntades como en la falta de adquisición del derecho al aprovechamiento urbanístico. Que la sentencia se preguntara en primer lugar sobre la aplicabilidad del citado art. 87.2 tiene su lógica, ya que en realidad el incumplimiento del convenio se debió a la existencia de un ulterior cambio de planeamiento, que incidió sobre el mismo; al respecto, no debe olvidarse que el contenido del convenio se había incorporado a un plan, por lo que había adquirido su misma fuerza y eficacia ${ }^{22}$. Es decir, el

con incidencia sobre ese contrato.

Para López Pellicer, op. cit., pág. 102, a los convenios que las Administraciones públicas suscriban con los particulares se les aplicará la Ley 13/95, salvo que, como en el caso del urbanismo, exista una regulación peculiar. Pero ésta sólo existe en ciertas Comunidades Autónomas; de cualquier modo, los preceptos del TRLS reguladores de la responsabilidad por actos urbanisticos serán aplicables a algunos de los supuestos.

De acuerdo con J. Arozamena SIERra, op. cit., pág. 24, la regulación básica de los convenios urbanísticos debe buscarse en la legislación de contratos de las Administraciones Públicas; y añade, op. cit., pág. 18, que en Navarra dicha legislación de contratos actúa como Derecho supletorio.

22 Estariamos ante algo muy próximo al factum principis en los contratos administrativos. Sobre esta figura, véase E. GARCiA DE ENTERRIA y T. R. FERNÁNDEZ RodRigUEZ, Curso de Derecho Administrativo, I, 7. " ed., Civitas, Madrid, 1995, págs. 712-13. Pues bien, Parada Vázquez, Derecho Administrativo, op. cit., pág. 354, afirma que el factum principis está más próximo a la responsabilidad extracontractual que a la responsabilidad contractual.

La STS de 6 de abril de 1993 (A. 2616) también trata de un supuesto en que se incumple el convenio urbanistico como consecuencia de la aprobación posterior de un plan incompatible con dicho convenio. Se había pactado la cesión gratuita de terrenos con anterioridad a la aprobación del proyecto de reparcelación, compensándola 
TS en realidad se pregunta sobre la aplicación de una regla extracontractual, al entender externa al convenio la causa origen de la responsabilidad.

En todo caso, la sentencia, tras afirmar que no era de aplicación el art. 87 de la Ley del Suelo de 1976, se pregunta si eran o no aplicables los preceptos jurídico-civiles sobre responsabilidad por incumplimientos contractuales; pero se desestima la existencia de responsabilidad contractual con base en los arts. 1256 y $1124 \mathrm{CC}$, al haberse concedido al recurrente un plazo más que prudencial para el cumplimiento de las cargas urbanísticas y haberse incumplido el mismo. Lo lógico habría sido que el TS, tras concluir que no era aplicable el art. 87 de la Ley del Suelo de 1976, hubiera aplicado, en su caso, los preceptos reguladores de la responsabilidad contractual administrativa, como podía ser el art. 53 de la Ley de contratos del Estado de 1973 - equivalente al art. 114.3 de la Ley 13/95-, que establecía que la Administración debía abonar al contratista los daños y perjuicios que se le irrogaran en caso de incumplimiento del contrato por parte de aquélla ${ }^{23}$. En efecto, si la sentencia se cuestiona previamente la posible aplicación de la Ley del Suelo es porque considera que el convenio se vinculaba directamente a la función pública urbanística, de modo que no cabía aplicar el Derecho privado porque las cuestiones suscitadas en relación con los convenios son jurídico-administrativas, de acuerdo con el art. 234 del Texto refundido de 1976, equivalente al art. 303 del vigente Texto Refundido de 1992. En todo caso, posiblemente la sentencia acudió al Código Civil ante la parquedad de la regulación de estas cuestiones en la legislación de contratos entonces vigente parquedad que continúa en la Ley $13 / 95-24$.

con la edificabilidad equivalente en otros. Pero el polígono desapareció al haberse aprobado el nuevo Plan general.

En este caso, el TS emplea el art. 87.2 del TRLS de 1976. Entiende de este modo que los requisitos para la concurrencia de esta responsabilidad eran la existencia de derechos patrimonializados o de cesiones a compensar y la imputabilidad del daño a la Administración. La sentencia considera que, al haber retrasado la efectividad de las compensaciones hasta la aprobación del plan general, la Administración era responsable, ya que no era necesario esperar hasta ver si cabia o no compensar la cesión tras la aprobación del nuevo planeamiento, por cuanto la parte de finca cedida formaba parte del sistema general (red viaria) y, por tanto, la compensación era independiente de la equidistribución de beneficios y cargas del resto de la finca.

La STS de 9 de mayo de 1976 (A. 3991), si bien desestimó la pretensión indemnizatoria por cuanto la misma iba anudada a la de anulación del plan —que no se produjo en ese caso- afirmó que en esa ocasión se daban los presupuestos de la responsabilidad de la Administración. Se trataba de un convenio por el que se cedian terrenos para equipamientos públicos a cambio de obtener la edificabilidad de otro terreno. Dicho convenio se incorporó a un plan parcial, pero poco después se aprobó un nuevo plan general en que no se reconocía dicha edificabilidad. El TS, si bien parte de que, como regla general, la responsabilidad sólo es exigible en los casos previstos en la Ley del Suelo, añade que en este caso concreto se habia producido un enriquecimiento para la Administración que obligaba a compensar al particular.

23 Démonos cuenta de que el precepto, a diferencia del art. 1101 y del art. $1124 \mathrm{CC}$, no hace alusión a la culpabilidad de la Administración, si bien deben tenerse en cuenta las disposiciones de la LCAP relativas a los casos en que concurre fuerza mayor. 
RESPONSABILIDAD PATRIMONIAL DE LA ADMINISTRACIÓN ...

Es posible que el TS se viera influido en este punto por el planteamiento efectuado por los recurrentes. Pero no es menos cierto que nuestros Tribunales son a veces proclives a aplicar a la Administración el régimen de responsabilidad del Código Civil ${ }^{25}$.

En resumen, la jurisprudencia del TS sobre responsabilidad patrimonial de la Administración por incumplimiento de convenios urbanísticos suele, en primer lugar, tratar de vincular esa responsabilidad a la aprobación de un plan posterior que impide el cumplimiento del convenio incorporado a un plan, reconduciendo así el supuesto a la regulación prevista en la Ley del Suelo; pero, cuando de ese modo no puede imputarse responsabilidad alguna, acude en ocasiones a las normas jurídico-civiles en materia de responsabilidad contractual.

En todo caso, es posible que esa apelación a las normas jurídico-civiles reguladoras de la responsabilidad contractual, culposa por tanto, se deba a la inercia de la regulación de la Ley del Suelo de 1976. En efecto, en esta norma la responsabilidad, si bien no se decía culposa de modo expreso, sí dejaba atisbar la existencia de ciertos ingredientes subjetivos, ya que la misma se vinculaba, bien a la revisión anticipada del planeamiento, bien a la falta de ejecución del mismo por causa imputable a la Administración. En todo caso, si, como ha puesto de relieve SeVILlaMerino ${ }^{26}$, el Texto Refundido de la Ley del Suelo de 1992 ha supuesto una objetivización de la responsabilidad del autor del plan,

los contratos administrativos. Por su parte, el art. 67 admite que las causas de nulidad del Derecho Civil se apliquen a los contratos administrativos.

La STS de 7 de noviembre de 1990 (A. 8805), antes citada, asimismo aplica a un convenio urbanístico los preceptos del Código Civil referentes a la anulación del contrato por error al prestar el consentimiento.

25 Ello ocurre, sobre todo, en los casos en que dicha responsabilidad concurre con la de particulares, en cuyo caso la Sala de lo Civil del TS tradicionalmente ha venido entendiéndose competente - véase MuÑoz MACHADO, op. cit., págs. 95 y ss.-. En todo caso, el proyecto de LJCA de 30 de septiembre de 1995 trato de cortar esta tendencia, al intentar modificar el art. 154 LEC y atribuir sin excepciones las cuestiones de responsabilidad patrimonial de la Administración al orden contencioso-administrativo, en la línea por otra parte reiniciada en el art. 144 de la Ley 30/92.

26 Op. cit., pág. 110; vid. asimismo pág. 138.

Por el contrario, A. Blasco ESTEVE, «Indemnización por modificación o revisión de los planes de urba-

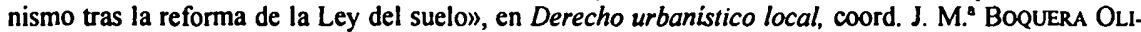
VER, Civitas, Madrid, 1992, pág. 450, considera que los requisitos de revisión anticipada o inejecución imputable a la Administración siguen vigentes. En relación con lo primero, se basa el autor en la adquisición gradual de facultades urbanísticas, lo que debe hacerse en los plazos seffalados en el propio planeamiento y la legislación autonómica y en su defecto en la Ley del suelo; en relación con lo segundo, afirma que, en caso de que la inejecución se deba a causas imputables a la Administración, las facultades urbanísticas no se pierden. Pero imputabilidad no equivale a culpabilidad. Es más, en el art. 237.3 se establece la indemnizabilidad de la pérdida de aprovechamiento aun en aquellos casos en que no se haya solicitado licencia de edificación dentro de plazo, si la edificabilidad se ha reducido en al menos un $50 \%$ respecto del aprovechamiento ya adquirido. 
ello también debe aplicarse, a mi juicio, al caso de los convenios urbanísticos. En efecto, en el art. 237 del TRLS de 1992 se dice que habrá responsabilidad por cambio de planeamiento siempre que se haya producido una disminución del aprovechamiento urbanístico, sin vincularla por tanto a aquellos elementos de índole subjetiva. Todavía más, en este ámbito los matices culposos sólo habrían sido admisibles, bajo la Ley del Suelo de 1976, en los casos en que el incumplimiento derivara de la alteración del planeamiento; $y$, aun en este caso, hay que tener en cuenta que imputabilidad no equivale exactamente a culpabilidad.

Podemos en todo caso preguntarnos si resulta lógica la aplicación a esta clase de convenios de las reglas reguladoras de la responsabilidad contractual, sean civiles o administrativas, dado que en ocasiones el convenio urbanístico se ha calificado como un supuesto de terminación convencional del procedimiento administrativo, equivalente para algunos a un sustitutivo del acto unilateral. Desde esta perspectiva, podría entenderse que la responsabilidad derivada del convenio no es en ciertos casos contractual, sino extracontractual ${ }^{27}$. Pero debe tenerse en cuenta que los convenios que pretenden una modificación del planea-

27 Contra esta opinión, I. SEVLLA MERINo, La responsabilidad patrimonial de la Administración por la aprobación de los planes urbanisticos municipales, FVMP-Civitas, Valencia, 1994, pág. 126.

Podemos también plantearnos qué ocurriria si el incumplimiento del convenio no obedeciera a un cambio de planeamiento, sino a una decisión unilateral de la Administración revocatoria de dicho convenio. En la medida en que el contenido del convenio no sea reglamentario, lo procedente será la revisión de oficio o la declaración de lesividad, por lo que serían aplicables las previsiones contenidas en el art. 102.3 de la Ley $30 / 92$ - vid. art. 65 de la Ley 13/95 - La revocación pura sería claramente ilegal, por lo que los interesados podrian solicitar su anulación y, en su caso, el resarcimiento de perjuicios, asimismo conforme a las reglas generales, salvo que se haya producido un cambio de planeamiento - téngase en cuenta que con carácter general no está sin más prevista la resolución por razones de interés público; véase no obstante lo que dispone el art. 168 de la LCAP para el contrato de gestión de los servicios públicos, o el art. 150 para el de obras; el art. 102 de esta Ley si permite a la Administración modificar el contrato por razones de interés público- $\mathrm{O}$, incluso, la responsabilidad será exigible en ocasiones de acuerdo con las reglas especificas establecidas en la Ley del Suelo, ya que el incumplimiento del convenio podria consistir, y consistirá muchas veces, en la ilegal denegación de una licencia amparada en el mismo, cuando aquél se ha incorporado a un plan.

En relación con esto, sería posible - véase MonToro CHINER, op. cit., págs. 195-96-que la denegación de la licencia fuera precedida del tiempo suficiente para hacer jugar el silencio positivo. Pero, tras la Ley 30/92, ya no cabe la revocación pura y simple de estas licencias, ya que el art. 242.6 del TRLS debe entenderse modificado por el art. 62.1 f) de la Ley $30 / 92$-como ha resaltado J. M. ${ }^{\text {a BOQUERA }}$ OLIVER, "La revisión de oficio de las concesiones y licencias urbanisticas», en REALA, n. ${ }^{\circ} 258,1993$, págs. 239 y ss. - . Éste seria, pues, un caso de denegación ilegal.

La demora en el otorgamiento de licencia amparada en el convenio podría, por otra parte, dar lugar a la extinción de la licencia por haberse aprobado durante la demora el nuevo planeamiento. Como afirma F. J. DeLGADo BARro, El control de la discrecionalidad del planeamiento urbanistico, Cuademos Civitas, Madrid, 1993, págs. 34 y ss., tras LRRUVS ya no cabe aplicar la solución jurisprudencial, también propugnada en su momento por MONTORO CHINER -op. cit., págs. 209 y s.- de aplicar en estos casos el planeamiento anterior. El problema es si la responsabilidad debería en estos casos exigirse por alteración del planeamiento o por demora en el otorgamiento de la licencia —art. 240 TRLS—. Esto último es lo más plausible. 
miento, que son los que aqui nos interesan, no constituyen propiamente un caso de terminación convencional del procedimiento, como hemos visto ${ }^{28}$.

Lo que ocurre es que la Ley del Suelo no contempla expresamente los casos de responsabilidad derivada del incumplimiento del convenio, como no sean aquéllos en que dicho incumplimiento del convenio incorporado a un plan tiene su base en la aprobación de un planeamiento posterior. Estos supuestos son en realidad casos de responsabilidad por cambio de planeamiento, regulados en el art. 237 del Texto refundido de la Ley del Suelo de 1992; y justamente estos supuestos tienen más similitudes con la responsabilidad extracontractual que con la contractual ${ }^{29}$. Pero la responsabilidad se dará en tales casos siempre que se produzca una disminución del aprovechamiento urbanístico adquirido, con independencia de la existencia o no de un convenio previo.

\section{EL CONTENIDO DE LA INDEMNIZACIÓN EN CASO DE INCUMPLIMIENTO DE CONVENIOS URBANISTICOS QUE AFECTEN A LA POTESTAD DE PLANEAMIENTO}

El convenio que afecta a la potestad de planeamiento no es vinculante para la Administración ni para el particular mientras no se aprueba como Plan, pero

28 No obstante, debe tenerse en cuenta que serán normalmente los terceros ajenos al convenio quienes podrian exigir responsabilidades por daños causados a consecuencia del mismo, por lo que en estos casos la responsabilidad no podrá calificarse de contractual.

29 En todo caso, cabria diferenciar entre los casos en que la revisión del plan, en lo que afecta al convenio, es o no conforme a Derecho. Pero la responsabilidad patrimonial también puede deberse a actos normativos licitos.

Otro supuesto podria ser que, de acuerdo con un convenio urbanistico, se otorgara una licencia que después se declarara ilegal. En estos casos, habrá que distinguir según el perjudicado sea el titular de la licencia $\rightarrow$ si no ha concurrido culpa por su parte o si, pese a la compensación de culpas, la Administración no queda totalmente exonerada; vid M. J. MONTORO CHINER, La responsabilidad de la Administración por actos urbanisticas, cit, pág. 348, para quien la compensación puede operar sólo en caso de dolo, culpa o negligencia leves del perjudicadoo los terceros. Pero, en todo caso, la simple anulación no origina responsabilidad, si no se ha producido perjuicio.

Los casos de extinción de la licencia otorgada al amparo del convenio por cambio de planeamiento son subsumibles en el art. 238 TRLS. En todo caso, SEVLLA Merino, op. cit., págs. 131 y ss., entiende que en el párrafo primero estamos ante un caso de responsabilidad del legislador, ya que entiende que dicha extinción se produce ope legis.

Pensemos también en el supuesto de que, al amparo de un convenio urbanistico, la Administración asumiera el cumplimiento de subvencionar la conservación de un edificio sujeto a vinculación singular. En realidad, las vinculaciones singulares son indemnizables, pero podría pactarse que, en lugar de la indemnización, corrieran a cargo de la Administración ciertos gastos o actuaciones de conservación. Es posible que el incumplimiento de este convenio diera lugar a la imposibilidad de conservar el edificio por falta de capacidad económica del propietario; lo que incluso podria perjudicar a los eventuales arrendatarios del mismo, que, en caso de ruina, verian extinguidos sus contratos de inquilinato. En estos casos, podemos preguntamos si la responsabilidad sería exigible al amparo del art. 239 TRLS. El supuesto no es exactamente el mismo, ya que la responsabilidad patrimonial no deriva directamente de la vinculación singular, sino de los daños causados por la inactividad administrativa en el cumplimiento del convenio. 
podría originarse responsabilidad administrativa si se hubiera lesionado el principio de confianza legítima ${ }^{30}$.

Pensemos en un convenio concertado entre el particular y el municipio que se pretende incorporar al contenido de un futuro plan de urbanismo, como es el caso antes comentado. En este supuesto, el contenido del convenio no vinculará a la Administración que haya de aprobar el plan definitivamente si el mismo afecta a sus intereses o aquélla considera que el convenio es contrario a Derecho, ya que, de acuerdo con la STS de 13 de julio de 1990 y otras posteriores las facultades autonómicas en la aprobación definitiva de los planes de urbanismo se hallan limitadas al control de legalidad, y sólo podrán extenderse al control de oportunidad en la medida en que se hallen afectados intereses supralocales ${ }^{3 f}$. En estos casos, no se habrá lesionado el principio de confianza legítima si la Administración municipal deja clara la posibilidad de no asunción de su contenido por la Administración que tiene encomendada la aprobación definitiva del plan ${ }^{32}$.

En todo caso, posiblemente en este supuesto la indemnización no vaya más allá del mero reembolso de los gastos del art. 241 del Texto refundido de la Ley del Suelo, ya que el particular no ha adquirido todavía derecho alguno, al no haberse producido la aprobación del Plan ${ }^{33}$.

Por el contrario, cuando la responsabilidad se derive de la aprobación de un plan posterior que incide sobre un convenio urbanístico cuyo contenido se ha in-

30 Sobre este principio, vid. R. GARCia MACHO, «Contenido y límites del principio de la confianza legitima: estudio sistemático en la jurisprudencia del Tribunal de Justicia), en REDA, n. ${ }^{\circ} 56,1987$, págs. 557 y ss.

31 En este sentido pueden verse, entre otras, las SSTS de 25 de febrero de 1992 (A. 2974), 18 de mayo de 1992 (A. 4219), 8 de febrerc de 1993 (A. 588), 19 de mayo de 1993 (A. 3499), 14 de junio de 1993 (A. 5022), 21 de septiembre de 1993 (A. 6623), 21 de febrero de 1994 (A. 1455), 17 de octubre de 1995 (A. 7704) y 25 de octubre de 1995 (A. 7711 ).

Por el contrario, la STS de 11 de marzo de 1993 (A. 1602) sugiere unas facultades autonómicas más amplias.

32 En todo caso, en virtud del principio de indisponibilidad de la potestad de planeamiento, el convenio propiamente tampoco vincularia a la que lo hubiera concertado hasta que el mismo se aprobara como plan, sin perjuicio de su responsabilidad. Vid. art. 75 de la Ley madrileña antes citada.

33 Para MONToro Chiner, op. cit., págs. 251 y ss. y 270 y ss., en alguna ocasión la indemnización podria ir mas allá, como en los casos en que el perjudicado hubiera adquirido los terrenos y cumplido sus deberes urbanisticos. Pero la adquisición de terrenos se puede incluir entre los gastos; y el cumplimiento de los deberes urbanísticos presupone la existencia de un previo plan. Es posible, en relación con lo segundo, que el convenio pretenda la modificación de un plan previo. Puede que el particular cumpla las cargas urbanísticas derivadas del mismo, y que éstas sean total o parcialmente coincidentes con las que suponga el futuro plan, y que las cumpla precisamente para conseguir los beneficios que se deriven del convenio. Pero si el nuevo plan no se aprobara, no por ello se habrán perdido los derechos adquiridos con arreglo al plan anterior no modificado. 
RESPONSABILIDAD PATRIMONIAL DE LA ADMINISTRACIÓN ...

corporado a otro plan previo disminuyendo el aprovechamiento efectivamente adquirido, dicha responsabilidad será subsumible en el art. 237 del Texto refundido de la Ley del Suelo, por lo que la indemnización será equivalente a la pérdida de aprovechamiento urbanístico efectivamente adquirido ${ }^{34}$. Asimismo, cabría que en estos supuestos se produjera la extinción de una licencia, en cuyo caso sería aplicable el art. 238. Pero en estos casos la responsabilidad se habrá originado con independencia de la preexistencia o no de un convenio, ya que lo único relevante es la pérdida de aprovechamiento o la extinción de la licencia.

\title{
6. CONCURRENCIA DE RESPONSABILIDADES DE DISTINTAS ADMINISTRACIONES PÚBLICAS
}

Aun cuando existan varias Administraciones que pueden haber concurrido a la causación del daño, el TS suele buscar, como por lo demás hace también en otros supuestos, una única responsable, que suele ser la municipal, partícipe en el convenio incumplido ${ }^{35}$.

Quizá haya que distinguir en este punto entre la sentencia de 18 de julio de 1994 y las restantes. En efecto, en esta sentencia el contenido del convenio se incorporó a la documentación de un plan que había de ser aprobado definitivamente por el Ministerio ${ }^{36}$. El TS afirma que se produjo un daño porque el

\footnotetext{
34 En el caso de la falta de solicitud de licencia dentro de plazo, habrá que estar a la regla especial contenida en el mencionado precepto.

35 Sobre la jurisprudencia que imputa al municipio toda la responsabilidad por actos urbanísticos, véase Sevilla Merino, op. cit., págs. 156 y ss.

En todo caso, la STS de 19 de septiembre de 1994 (A. 677, 1995) declaró la ausencia de responsabilidad patrimonial del Ayuntamiento, ya que, de una parte, se trataba de la denegación de la aprobación inicial de un plan, a la que podria haberse seguido o no la aprobación definitiva; y, además, la razón de dicha denegación habia radicado en la existencia de iniciativas urbanísticas ajenas al Ayuntamiento y posteriores al convenio.
}

\begin{abstract}
36 Este supuesto se puede subsumir en los convenios previos al acto que pone fin al procedimiento administrativo, a que se refiere el art. 88 de la Ley $30 / 92$.

La sentencia de 9 de mayo de 1976 (A. 3991) es asimismo interesante porque el aprovechamiento urbanistico establecido en el plan parcial al que se habia incorporado el contenido del convenio no se ajustaba al planeamiento general vigente en el momento de su aprobación, no obstante lo cual el TS entiende que existia una clara voluntad de modificar el planeamiento, tratándose a su juicio de una «preaprobación» del cambio de destino, que, si bien carecia de eficacia transformadora de la realidad, debía tenerse en cuenta a efectos indemnizatorios, sobre todo por cuanto el nuevo Plan general se aprobaria muy poco tiempo después. En suma, la responsabilidad existe aun cuando el convenio era contrario al planeamiento en vigor, y aun cuando no era competente el mismo órgano para aprobar el Plan general que el que había aprobado el plan parcial.

El caso es similar al de la sentencia citada en el texto, ya que, si bien en este supuesto el convenio se incorporó a un plan parcial, según el TS éste constituia una especie de anticipación del nuevo planeamiento general, que no incorporó su contenido.
\end{abstract}


precio de la venta de los terrenos fue inferior al que podría haber sido de no haberse disminuido la edificabilidad a consecuencia de las modificaciones introducidas por el Ministerio respecto de lo convenido, por lo que declaró la responsabilidad del Municipio. Téngase en cuenta que, si bien desconocemos si tales modificaciones obedecieron a cuestiones de legalidad o a la existencia de afectación a intereses supralocales, la aprobación definitiva se produjo mucho antes de la Constitución y, por tanto, mucho antes de la consagración de la autonomía municipal tal y como hoy se entiende.

Realmente, desde el punto de vista subjetivo o de la culpabilidad, el único responsable es el Municipio, ya que el Ministerio fue ajeno al convenio y no sólo eso, sino que dicho convenio se formalizaría precisamente como «plan de ordenación de masas» sujeto a la aprobación definitiva del Ministerio. Es decir, el Municipio presta su consentimiento al convenio aun a sabiendas de que había que modificar el ordenamiento urbanístico vigente para su eficacia ${ }^{37}$. Sin embargo, desde el punto de vista objetivo, en la realización del daño también concurrió el Ministerio ${ }^{38}$. En efecto, la actuación municipal generó en el particular unas esperanzas que después se frustraron, al no incorporar el Ministerio al plan el contenido del convenio. Si el Ministerio hubiera efectuado esa incorporación, el daño no se habría producido; objetivamente pues, en la realización del daño concurre concausalmente la negativa de dicho órgano estatal. La ac-

37 Vid. art. 74 de la Ley madrileña de 25 de marzo de 1995 y art. 140.5 de la Ley navarra 6/94.

Aqui podria haberse incluso planteado la posible concurrencia de culpa del ciudadano que firmó el convenio, para atenuar la posible responsabilidad administrativa.

38 Es más, en el momento en que ocurrieron estos hechos, era muy fuerte la tutela del Estado sobre el Municipio, de modo que puede entenderse que en aquel momento la fiscalización se extendia sin problemas tanto a la legalidad como a la oportunidad; lo que, siguiendo a Sevilla Merino, op. cit., págs. 170 y ss., supondria entender que el Estado es, en su caso, responsable, al ser el verdadero autor del plan.

Para E. Garcia de Enterria y T. R. Fernández Rodriguez, Curso de Derecho Administrativo, $I l, 3 .^{\circ}$ ed., Civitas, Madrid, 1991, págs. 372 y ss., la finalidad garantizadora de la responsabilidad implica en más de una ocasión la separación de la imputabilidad y la causalidad - vid. SEVILLA MERINO, op. cit., pág. 153-. Estos autores, op. cit., pág. 388, entienden que la teoria de la equivalencia de las condiciones para la determinación de la relación causal podria en ciertos casos conducir a resultados injustos, por lo que prefieren utilizar la tesis de la causalidad adecuada, es decir, se requiere que la actuación sea en sí misma idónea para producir un resultado lesivo. No obstante, antaden que en casos de concurrencia de posibles diversas causas, como el que nos ocupa, el juez se ve muchas veces llevado a forzar el problema teórico de la causa, a fin de garantizar la indemnidad de la víctima. Podría pensarse que ello no es aplicable cuando la causa adecuada es la actuación de una Administración, e incide asimismo tangencialmente una conducta de otra, ya que la primera seria solvente. Pero los Ayuntamientos adolecen de una crónica carencia de recursos. En todo caso, en la famosa STS de 25 de enero de 1974, sobre demolición de un hotel cercano a un aeropuerto, el Estado fue condenado por haberse apreciado negligencia en su actuación a la hora de aclarar que el hotel entonces en construcción infringia las normas sobre alturas máximas permisibles en las cercanias de esos lugares. Es decir, la relación causal entre la omisión y el daño parece configurarse en la medida en que concurrió negligencia en la actuación del Ministerio. Pero la culpa no forma parte del sistema general de responsabilidad de la Administración. 
RESPONSABLLLDAD PATRIMONIAL DE LA ADMINISTRACIÓN ...

tuación ministerial es perfectamente lícita y conforme a Derecho, ya que el Municipio no podía imponer su voluntad al Ministerio, teniendo en cuenta sobre todo que los hechos fueron muy anteriores a la consagración constitucional de la autonomía municipal. Pero no hay duda de que aquél ha intervenido concausalmente en la producción de un daño.

En relación con esto, MuÑoz MACHADO ${ }^{39}$ entiende que el solo ejercicio de las facultades de tutela de un ente sobre otro no convierten al primero en responsable cuando ratifica los actos del tutelado, ya que del mismo modo que la anulación de un acto no implica sin más la responsabilidad, tampoco la conlleva sin más su ratificación. De cualquier modo, el autor ${ }^{40}$ señala que cuando varias Administraciones intervienen en una decisión y la participación de una de ellas es esencial, de modo que sin la misma la decisión no se habría adoptado o habría tenido un sentido muy diferente, ambas serán responsables. Es decir, MuÑOZ MACHADO distingue el supuesto de la participación de varias Administraciones en la adopción de una decisión del más especial de la tutela de mera legalidad; pues bien, en el caso de autos la relación iba más allá de esta última, ya que antes de la Constitución el Ministerio era el verdadero autor del plan, en cuanto que sus facultades se extendían tanto al control de legalidad como al de oportunidad, fueran cuales fueran los intereses afectados ${ }^{41}$. Si lo hubiera aprobado en los términos convenidos por el Ayuntamiento, el daño no se habría producido 42 .

En cualquier caso, debe tenerse en cuenta en este punto las facultades que hoy día tienen las Comunidades Autónomas sobre la aprobación definitiva de los planes de urbanismo ${ }^{43}$. El TS, a partir de la sentencia de 13 de julio de 1990, afirma constantemente que dichas facultades no son omnímodas, sino

39 Op. cit., págs. 152 y ss. Por mi parte, entiendo sin embargo que el art. 142.4 quiere decir que la indemnización sólo será procedente si dicha anulación ha producido un daño -es decir, si se da relación de causalidad_ y la posible culpa de la víctima no exonera totalmente a la Administración; además, supone el precepto que la Administración autora del acto anulado también puede ser responsable, y no sólo la que lo anule, que sólo lo será cuando se den las circunstancias apuntadas.

40

Op. cit., pág. 176.

41 En la actualidad, todo dependerá de si se considera o no correcta la postura que hoy día sigue mayoritariamente el Tribunal Supremo.

42 No creo que haya que adoptar un criterio de causalidad distinto para las acciones que para las omisiones, al menos como regla general. Es más, en el caso de que el Ministerio hubiera ratificado la actuación municipal y ello hubiera causado un daño a terceros ajenos al convenio, para determinar la responsabilidad del Ministerio tendria que haberse tenido en cuenta sus facultades en la aprobación definitiva, que en aquel momento afectaban tanto a la legalidad como a la oportunidad.

43 La STS de 13 de febrero de 1992 (A. 2828) afirma que, dado que la potestad de planificación urbanística es compartida, los convenios nunca podrían limitar el contenido de las competencias autonómicas. De modo similar se expresa la STS de 30 de abril de 1990 (A. 3624). 
que, en aras de la autonomía local, se circunscriben al control de legalidad, mientras que el control de oportunidad sólo será posible cuando resulten afectados intereses supralocales ${ }^{44}$. Esto significa que, hoy día, si en la aprobación provisional se incluye el contenido de un convenio, la Comunidad Autónoma estará obligada a respetar ese contenido salvo que sea contrario a Derecho o salvo que resulten afectados intereses supralocales.

Si tal contenido no se respeta por haber existido extralimitación de las facultades autonómicas, no solamente podrá solicitarse en vía jurisdiccional la anulación de las modificaciones efectuadas en la aprobación definitiva, sino que, además, podrá existir responsabilidad patrimonial de la Comunidad Autónoma por una actuación normativa ilícita si la misma ha producido un daño. En caso de que la Comunidad Autónoma se haya apartado de lo aprobado provisionalmente por ser ilícito su contenido, no parece que puedan exigírsele responsabilidades. En este supuesto, el Ayuntamiento habrá generado, con la celebración del convenio, unas expectativas que no se pueden respetar por ser dicho convenio contrario a Derecho; por lo que cabe sostener la responsabilidad de la Administración municipal, que no obstante podrá compensarse o incluso exonerarse si ha concurrido culpa de la otra parte en el convenio ${ }^{45}$. En tercer lugar, si la Comunidad Autónoma no ratifica en la aprobación definitiva el contenido del convenio por existir implicados intereses supralocales y no parecerle esa solución la más conveniente, es evidente que su actuación habrá sido lícita.

Pero, aun así, esta actuación normativa lícita habrá concurrido concausalmente en la producción de un daño, por lo que en la relación externa con la otra parte en el convenio será responsable, sin perjuicio de que en el reparto interno de responsabilidades pueda no entenderse así ${ }^{46}$.

\footnotetext{
44 La sentencia, asi como las posteriores que siguen su doctrina, afirma asimismo que el margen de apreciación de los conceptos juridicos indeterminados se deberá respetar por la Comunidad Autónoma cuando no se hallen implicados intereses supralocales, pero cuando tales intereses se hallen afectados la Comunidad Autónoma se hallará vinculada a la concreción efectuada por el Ayuntamiento.

En el mismo sentido puede verse, entre otras muchas, la STS de 18 de marzo de 1992.

45 Para Mữoz Machado, op. cit., pág. 177, no pueden exigirse responsabilidades al ente de tutela que considera válido un acto que después resulta contrario al Ordenamiento, salvo que la ilegalidad causante del daño fuera flagrante. Vid. asimismo SEvilla Merino, op. cit., págs. 157 y ss., donde insiste en que el plan no es municipal porque el control autonómico va más allá de la pura legalidad.

Según este último autor, op. cit., pág. 119, en el ámbito urbanístico la responsabilidad administrativa queda enervada siempre que concurra culpa de la victima, salvo en el caso de que el particular no haya solicitado a tiempo licencia. Pero en la sentencia que comentamos, se declaró la responsabilidad patrimonial de la Administración, a pesar de que dificilmente puede no hablarse en este supuesto de culpa de la otra parte en el convenio.
}

46 Debe tenerse en cuenta que, como afirma Muñoz MaChado, op. cit., págs. 184 y ss., la determinación de las respectivas responsabilidades es más dificil en la responsabilidad objetiva que en la subjetiva. Todavia más, habria que preguntarse si, siendo la responsabilidad objetiva, cabria repartir interna- 
RESPONSABILIDAD PATRIMONIAL DE LA ADMINISTRACIÓN ...

En todo caso, en el caso resuelto por la STS de 18 de julio de 1994 el recurrente sólo demandó la responsabilidad de la Administración municipal, que fue la única que declaró la Sala.

En cambio, en el caso de la STS de 15 de febrero de 1994 tenemos un convenio conforme a la ordenación urbanística entonces vigente que, sin embargo, no se puede cumplir por haberse producido un cambio de planeamiento. Es decir, tenemos un convenio ya incorporado a un plan y que no se puede cumplir porque la Administración urbanística ha ejercitado su potestas variandi. El ejercicio de esta potestad es perfectamente legítimo, pero causa un daño patrimonial si se produce una disminución del aprovechamiento urbanístico. En todo caso, este daño patrimonial, y la responsabilidad subsiguiente, es en realidad independiente de la existencia o no de un previo convenio urbanístico, ya que lo importante es la existencia de una disminución del aprovechamiento a consecuencia del cambio de planeamiento, de acuerdo con el art. 237 del Texto refundido de la Ley del Suelo de 1992.

Es decir, desde el momento en que el convenio se incorpora al plan, tiene la misma fuerza y eficacia que éste. El contenido del convenio obliga pues en estos casos porque es plan. Por esta razón, la responsabilidad, si existe, en caso de cambio de planeamiento, se regirá por lo dispuesto en el art. 237 citado ${ }^{47}$.

Desde el punto de vista objetivo, habrá que determinar quién es el responsable según el criterio de las respectivas competencias; $y$, cuando no sea posible, la regla habrá de ser la solidaridad ${ }^{48}$. Es decir, si aquellos conte-

mente la carga entre las dos Administraciones según el grado de culpabilidad, si la hubiera habido. No debe al respecto olvidarse que la responsabilidad objetiva tiene ante todo una finalidad garantizadora en relación con el ciudadano; ni tampoco la posibilidad de ejercitar acciones de regreso contra autoridades o funcionarios, que podrian incluso abarcar la totalidad de la indemnización. La culpabilidad, si la hay, puede ser un criterio interno de reparto, sin perjuicio de que de cara al particular la responsabilidad sea objetiva y sin perjuicio de que, si no existe culpabilidad alguna, el reparto se haga con base en criterios objetivos de imputación que tengan en cuenta la medida de la concausalidad.

47 En este caso, no serán aplicables los preceptos autonómicos, como la citada Disposición Adicional Cuarta de la Ley valenciana, que exoneran a la Administración de responsabilidad por no haber incorporado a un plan ulterior el contenido del convenio, ya que el supuesto es muy diferente: en este caso, se ha efectuado la incorporación, pero el plan que recoge el contenido del convenio es alterado por otro posterior.

48 Véase Mũ̃oz Machado, op. cit., págs. 171 y ss.; Sevilla Merino, op. cit., págs. 171 y ss.

La STS de 15 de noviembre de 1993 (A. 10115), en un supuesto de responsabilidad por cambio de planeamiento, afirma la responsabilidad solidaria de la Administración autonómica y municipal, a fin de otorgar una máxima protección a los particulares afectados. La sentencia efectúa una interpretación amplia de las «fórmulas colegiadas de actuación» a que se refiere el art. 140 de la Ley 30/92 — véase I. SEVILLA MERINo, La responsabilidad patrimonial de la Administración por la aprobación de los planes urbanisticos municipales, cit., pág. 164 . 
nidos de la revisión o de la modificación que inciden sobre el convenio previo se hallaban ya en la aprobación provisional del nuevo plan, el Municipio será el responsable ${ }^{49}$. Si por el contrario tales contenidos se incorporan en la aprobación definitiva, habrá que distinguir los mismos supuestos que en el caso anterior. Es decir, si el control efectuado es de oportunidad por hallarse afectados los intereses supralocales, la Administración responsable será la autonómica. Cuando el control lo sea de legalidad, la Comunidad Autónoma no será responsable, pero podría serlo el Municipio que fue parte en el convenio, sin perjuicio de la posibilidad de compensación de culpas si la otra parte incurrió en negligencia. Y, si la Comunidad Autónoma se extralimitara en sus facultades, sin perjuicio de la posibilidad de anulación en ese punto de la aprobación definitiva o de su denegación, cabría, en caso de que se hubiera producido un daño a consecuencia de su actuación, entenderla como única responsable.

Desde el punto de vista subjetivo, que puede ser importante a efectos del reparto interno de responsabilidades cuando a efectos externos hubiera que utilizar la regla de la solidaridad ${ }^{50}$, en primer lugar habría que distinguir según la iniciativa de la revisión o modificación en ese punto haya partido del Municipio o de la Comunidad Autónoma —o, quizá mejor, según cuáles sean los intereses afectados-; en segundo lugar, habría que ver si esa revisión ha sido o no anticipada, ya que, si no lo ha sido, cabria entender subjetivamente responsable al Municipio si éste se demoró en la ejecución de lo convenido ${ }^{51}$.

Sería lógico en todo caso que la sentencia de 15 de febrero de 1994 (A. 1448) se hubiera preguntado cuál de las dos Administraciones intervinientes en el proceso de elaboración de las Normas subsidiarias fue efectivamente la responsable ${ }^{52}$. El TS no lo hace, sino que declara sin problemas la

49 En todo caso, SEVILLA MERINo, op. cit., pág. 170, matiza que en realidad lo que debe prevalecer es el criterio del interés afectado, y no tanto si la decisión autonómica ha ratificado o no la municipal. Es decir, si la ratificación afecta a un interés supralocal, la responsabilidad será autonómica. Añade que, si por el contrario la Comunidad introdujera modificaciones de oportunidad en una cuestión atinente al interés local, sería responsable dicho Municipio, ya que entiende que esta última Administración habrá asumido esa medida a todos los efectos. La STS de 15 de noviembre de 1993, antes citada, afirma asimismo que a efectos del reparto interno de responsabilidades entre las dos Administraciones lo relevante no es tanto quién haya sido la autora del cambio como a qué interés - municipal o autonómico- se ha tratado de atender con el mismo.

El mismo autor efectúa por otra parte unas acertadas observaciones sobre la imputación de responsabilidades en los casos establecidos en el art. 244 TRLS.

so Véase el dictamen del Consejo de Estado de 1 de octubre de 1987.

51 No debe olvidarse en todo caso la posible modulación de la responsabilidad con base en la eventual concurrencia de culpas del particular, si la demora en dicha ejecución fuera en cierta medida imputable al mismo.

52 Véase I. SEVILLA MERINo, La responsabilidad patrimonial de la Administración por la aprobación 
RESPONSABILIDAD PATRIMONIAL DE LA ADMINISTRACIÓN ...

responsabilidad de la Administración municipal, menos solvente pero copartícipe del convenio y de la elaboración de las Normas subsidiarias. Quizá la sentencia siga la línea más frecuente en nuestra jurisprudencia en este punto, que busca, como ha resaltado MUÑOZ MACHADO ${ }^{53}$, la identificación de un único patrimonio responsable.

de los planes urbanísticos municipales, cit., págs. 153 y ss.

Asimismo, podemos plantearnos el supuesto, comentado por MONTORO CHINER, op.cit., págs. 235 y ss., en que la competencia urbanistica se superponga con algún otro título competencial. La autora subraya que, en caso de falta de coordinación que dé lugar a responsabilidad, en ocasiones la jurisprudencia hace recaer sobre el municipio la carga indemnizatoria, al ser la licencia municipal la última en obtenerse; y critica esta jurisprudencia señalando que la responsabilidad puede en realidad deberse a la actuación de otra Administración vinculante para la entidad local.

s3 Op. cit., págs. 26 y ss. 
